\title{
Update on the Genetic Polymorphisms of Drug-Metabolizing Enzymes in Antiepileptic Drug Therapy
}

\section{Junji Saruwatari $^{1}$, Takateru Ishitsu ${ }^{2}$ and Kazuko Nakagawa ${ }^{1,3, *}$}

1 Division of Pharmacology and Therapeutics, Graduate School of Pharmaceutical Sciences, Kumamoto University, Oe-honmachi 5-1, Kumamoto 862-0973, Japan;

E-Mail: junsaru@gpo.kumamoto-u.ac.jp (J.S.)

2 Kumamoto Saishunso National Hospital, Kumamoto, Suya 2659, Koshi, Japan; E-Mail: ishitsu@bf7.so-net.ne.jp (T.I.)

3 Center for Clinical Pharmaceutical Sciences, Kumamoto University, Oe-honmachi 5-1, Kumamoto 862-0973, Japan

* Author to whom correspondence should be addressed; E-Mail: kazukon@gpo.kumamoto-u.ac.jp; Tel./Fax: +81-96-371-4545.

Received: 31 May 2010; in revised form: 10 August 2010 / Accepted: 17 August 2010 / Published: 20 August 2010

Abstract: Genetic polymorphisms in the genes that encode drug-metabolizing enzymes are implicated in the inter-individual variability in the pharmacokinetics and pharmacodynamics of antiepileptic drugs (AEDs). However, the clinical impact of these polymorphisms on AED therapy still remains controversial. The defective alleles of cytochrome P450 (CYP) 2C9 and/or CYP2C19 could affect not only the pharmacokinetics, but also the pharmacodynamics of phenytoin therapy. CYP2C19 deficient genotypes were associated with the higher serum concentration of an active metabolite of clobazam, $N$-desmethylclobazam, and with the higher clinical efficacy of clobazam therapy than the other CYP2C19 genotypes. The defective alleles of CYP2C9 and/or CYP2C19 were also found to have clinically significant effects on the inter-individual variabilities in the population pharmacokinetics of phenobarbital, valproic acid and zonisamide. EPHX1 polymorphisms may be associated with the pharmacokinetics of carbamazepine and the risk of phenytoin-induced congenital malformations. Similarly, the UDP-glucuronosyltransferase 2B7 genotype may affect the pharmacokinetics of lamotrigine. Gluthatione S-transferase null genotypes are implicated in an increased risk of hepatotoxicity caused by carbamazepine and valproic acid. This article summarizes the state of research on the effects of mutations of drug- 
metabolizing enzymes on the pharmacokinetics and pharmacodynamics of AED therapies. Future directions for the dose-adjustment of AED are discussed.

Keywords: pharmacogenetics; genetic polymorphisms; antiepileptic drugs; drug-metabolizing enzyme; population pharmacokinetics

\section{Introduction}

Epilepsy is a disorder of the brain characterized by an enduring predisposition to generate epileptic seizures, and epileptogenesis is the development of a neuronal network in which spontaneous seizures occur [1-3]. Epilepsy is a common chronic neurological disease, of which the worldwide prevalence is estimated to be $0.6-1.0 \%[1-3]$.

The treatment outcome for epilepsy with antiepileptic drugs (AEDs) may vary, even between patients with seemingly the same epilepsy syndrome [1,4]. It is estimated that $20-25 \%$ of patients with epilepsy fail to achieve good control with an AED [1,4,5]. Although the incidence of adverse effects differs among AEDs, it is currently not possible to predict the efficacy and adverse effects in an individual patient [6-9]. Some of the observed variability in individual responses to AEDs depends on well-known factors that are easily assessable, such as age, sex, weight, liver and renal function, co-medication, heterogeneity in the disease, nutritional state, and/or smoking status [10,11]. However, further differences in the response may, at least in part, result from the genetic variation in the patients [5-9,12].

Pharmacogenetics concerns the link between the genetic constitution of an individual and his/her reaction to drugs [10,13-16]. Although this discipline promises the possibility of one day choosing the right drug for any individual, i.e., effective treatment without major adverse effects at an effective dose, only a few of isolated examples has been available in clinical practice $[10,15,16]$. Among the AED therapies, the individual patient genotype influences almost all stages of pharmacokinetics and pharmacodynamics $[6,7,9,17-20]$.

The topic of pharmacogenetics in epilepsy has previously been covered in several excellent review articles [5,8,21-23]. In a review published in 2009, the impact of genetic variations in drugmetabolizing enzymes was concluded to have a limited clinical impact on AED therapy [7]. The aim of the present article was to provide a more recent update on the clinical impact of genetic polymorphisms of drug-metabolizing enzymes on the pharmacokinetics and pharmacodynamics of AEDs. Future directions for the AED dose-adjustment according to both genetic and non-genetic factors affecting the pharmacokinetics of AEDs are also discussed.

\section{Search Strategy and Selection Criteria}

We identified articles through a system search of the Ovid MEDLINE database and through reference lists of selected articles up to April 30, 2010. The following terms were used for the MEDLINE search: (epilepsy [MeSH terms] OR anticonvulsants [MeSH terms] OR antiepileptic drug[All Fields] OR carbamazepine [All Fields] OR clobazam [All Fields] OR clonazepam [All Fields] OR ethosuximide [All Fields] OR felbamate [All Fields] OR gabapentin [All Fields] OR lamotrigine [All Fields] OR 
levetiracetam [All Fields] OR oxcarbazepine [All Fields] OR phenobarbital [All Fields] OR phenytoin [All Fields] OR primidone [All Fields] OR topiramate [All Fields] OR valproic acid [All Fields] OR valproate [All Fields] OR zonisamide [All Fields]) AND (pharmacokinetics [MeSH terms] OR drugmetabolizing enzyme [All Fields] OR cytochrome P450 [All Fields] OR epoxide hydrolase [All Fields] OR glucuronosyltransferase [All Fields] OR glutathione transferase [All Fields]) AND (pharmacogenetics [All Fields] OR pharmacogenomics [All Fields] OR genetic [All Fields] OR polymorphism [All Fields] genotype [All Fields] OR allele [All Fields] OR mutation [All Fields]). Articles published between 1950 and 2010 were included. No language or ethnic restriction was applied for the search and study inclusion. We largely selected publications appeared in the past five years, but did not exclude commonly referenced and highly regarded older publications. Review articles are cited to provide readers with more details and references than are provided in this article.

\section{Pharmacokinetics of AEDs}

Older AEDs such as phenytoin, carbamazepine, valproic acid (sodium valproate) and phenobarbital are characterized by a narrow therapeutic range and a pronounced inter-individual variability in their pharmacokinetics $[11,22,24]$. It is often claimed that the new generation of AEDs such as gabapentin and levetiracetam have a major advantage over the older AEDs in that they have more predictable pharmacokinetics [11,25]. However, for some of newer AEDs such as clobazam, lamotrigine, topiramate and zonisamide, pharmacokinetic variability is just as prevalent as for many of the older AEDs $[22,25,26]$. Individualization of dosing has therefore been a key concept in the effort to optimize drug treatment of epilepsy, and measuring drug concentrations in serum or plasma via therapeutic drug monitoring has become a major focus of clinical research and practice [11,25].

Table 1 summarizes the pharmacokinetic characteristics of the various AEDs. Elimination of drugs, including AEDs, is accomplished by the hepatic (metabolism) and/or renal (excretion) route (Table 1) $[7,9,18,19]$. Since the metabolism of AEDs represents the prominent pathway of elimination (Table 1), both in qualitative and quantitative terms, the inter-individual capacity of hepatic metabolism of AEDs is the primary cause of the variability in the pharmacokinetics, and even in the pharmacodynamics (i.e., efficacy, tolerability and safety) of the AEDs [18,19].

\section{Genetic Polymorphisms of Drug-Metabolizing Enzymes}

\subsection{Cytochrome P450 (CYP) superfamily}

The CYP enzymes are encoded by 57 human genes whose products are involved in oxidative drug metabolism, as well as the synthesis of cholesterol, steroids, prostacyclins and thromboxanes. In the last few years, CYP enzymes have attracted increasing attention, and it has been demonstrated that many CYPs have genetic polymorphisms [27-29]. Most AEDs, except for gabapentin, lamotrigine and levetiracetam, are metabolized at least partially by CYP enzymes (Table 1) [18]. Therefore, genetic polymorphisms of CYP enzymes are implicated in the inter-individual variability in the pharmacokinetics of AEDs [7,12,17-19]. 
Table 1. Pharmacokinetic characteristics of antiepileptic drugs.

\begin{tabular}{|c|c|c|c|c|c|}
\hline AED & $\begin{array}{l}\text { Oral } \\
\text { bioavailability }\end{array}$ & $\begin{array}{l}t_{1 / 2} \\
\text { (hour) }\end{array}$ & Clearance & Active metabolites & $\begin{array}{l}\text { Enzymes involved in the } \\
\text { metabolism of the compound }\end{array}$ \\
\hline Carbamazepine & $75-85 \%$ & $12-24$ & $>95 \%$ Hepatic & Carbamazepine-10,11-epoxid & e CYP3A4/5, CYP2C $8, \mathrm{mEH}, \mathrm{UGTs}$ \\
\hline Clobazam & $87 \%$ & $22-30$ & $>95 \%$ Hepatic & $N$-desmethylclobazam & CYP3A4 and CYP2C19 \\
\hline Clonazepam & $>80 \%$ & $19-60$ & $>95 \%$ Hepatic & - & CYP3A4 \\
\hline \multirow[t]{2}{*}{ Ethosuximide } & $<100 \%$ & $36-60$ & $65 \%$ Hepatic & - & CYP3A4 \\
\hline & & & $35 \%$ Renal & & \\
\hline \multirow[t]{2}{*}{ Felbamate } & $90 \%$ & $14-23$ & $50 \%$ Hepatic & - & CYP2C19?, UGTs \\
\hline & & & $50 \%$ Renal & & \\
\hline Gabapentin & $45-70 \%$ & $5-7$ & $100 \%$ Renal & - & None \\
\hline \multirow[t]{2}{*}{ Lamotrigine } & $<100 \%$ & $24-36$ & 90\% Hepatic & - & UGTs \\
\hline & & & $10 \%$ Renal & & \\
\hline \multirow[t]{2}{*}{ Levetiracetam } & $<100 \%$ & $6-8$ & $66 \%$ Renal & - & Nonhepatic hydrolysis (in blood) \\
\hline & & & $34 \%$ Hepatic & & \\
\hline \multirow[t]{2}{*}{ Oxcarbazepine } & $>95 \%$ & $1-2$ & $45 \%$ Hepatic & MHD & UGTs \\
\hline & & & $65 \%$ Renal & & \\
\hline \multirow[t]{2}{*}{ Phenobarbital } & $80-100 \%$ & $72-96$ & 75\% Hepatic & - & CYP2C19, СYР2C9 \\
\hline & & & $25 \%$ Renal & & \\
\hline Phenytoin & $95 \%$ & $20-50$ & $>90 \%$ Hepatic & - & СYР2C9, СYР2C19 \\
\hline \multirow[t]{2}{*}{ Primidone } & $<100 \%$ & $10-20$ & $50 \%$ Hepatic & Phenobarbital & CYP2C9 (for phenobarbital) \\
\hline & & & $50 \%$ Renal & Phenylethylmalonamide & \\
\hline \multirow[t]{2}{*}{ Topiramate } & $80 \%$ & $20-30$ & $30-50 \%$ Hepatic & - & CYP3A4, UGTs \\
\hline & & & $50-70 \%$ Renal & & \\
\hline Valproic acid & $<100 \%$ & $8-16$ & $>95 \%$ Hepatic & - & UGTs, CYP2C9, CYP2C19 \\
\hline Zonisamide & $<100 \%$ & $50-70$ & $>90 \%$ Hepatic & - & CYP3A4, CYP2C19, UGTs \\
\hline
\end{tabular}

This table is prepared based on the previous review articles $[7,22,25,26]$ with modifications. AED, antiepileptic drug; $\mathrm{t}_{1 / 2}$, elimination half-life; CYP, cytochrome P450; $\mathrm{mEH}$, microsomal epoxide hydrolase; UGTs, UDP-glucuronosyltransferases; MHD, monohydroxylated active metabolite of oxycarbazepin.

CYP2C9 and CYP2C19 have well-characterized functional variants. The frequencies of defective CYP2C9 alleles (CYP2C9*2 and CYP2C9*3) are higher in Caucasians (18.9\%) than in Asians (2.5-3.5\%) [30,31]. Conversely, the frequencies of defective CYP2C19 alleles (CYP2C19*2 and CYP2C19*3) are higher in Asians (33-43.5\%) than Caucasians (13.6\%) [30-32]. Population studies have shown that individuals can be classified into three subgroups: homozygous extensive metabolizers (homo EMs), heterozygous EMs (hetero EMs) and poor metabolizers (PMs) according to the number (i.e., 0, 1 and 2, respectively) of the defective alleles(s) of each CYP2C gene [12,30-32]. Individuals with defective alleles of the CYP2C9 or CYP2C19 genes have been shown to have a reduced metabolism of some AEDs compared with those with wild-type (normal) alleles [7,17-19,33-39].

In addition to CYP2C9/2C19, CYP3A5 is polymorphically expressed in the liver, small intestine and kidney, and represents 5 to $85 \%$ of the total hepatic and intestinal CYP3A4/5 content [40-42]. The most common CYP3A5 polymorphism is CYP3A5*3, which has a frequency of $65-85 \%$ in Asians, 84-95\% in Caucasians and 27-55\% in African-Americans [30,31,40-42]. This allele contains a splice variant, which encodes a truncated nonfunctional protein [40-42]. Regardless of race, in vitro studies 
using human liver and intestine preparation have demonstrated that homozygosity for the CYP3A5*3 allele leads to decreased expression of CYP3A5 mRNA and protein in comparison with the heterozygous or homozygous wild-type $\left(C Y P 3 A 5^{*} 1\right)$ allele [40-42]. However, the clinical importance of $C Y P 3 A 5 * 3$ polymorphisms in pharmacokinetics of AEDs is not yet clear $[38,43,44]$.

\subsection{Microsomal epoxide hydrolase}

Oxidation by one or more of the phase I oxidative enzymes such as the CYP superfamily often results in the formation of reactive xenobiotic epoxide [45]. The microsomal epoxide hydrolase ( $\mathrm{mEH}$ ) encoded by EPHX1 is a biotransformation enzyme that metabolizes numerous reactive epoxide intermediates to more water-soluble trans-dihydrodiol derivatives [45]. Human $\mathrm{mEH}$ expression has been demonstrated in all of the tissues examined, with highest levels in the liver, kidney and testes [45-47] and 10- to 100 -fold lower levels in the lungs and lymphocytes [48].

Marked inter-individual variations in $\mathrm{mEH}$ activity have been reported [49]. These variations may be due to genetic polymorphisms in the coding regions as well as in the promoter region of the EPHX1 [45,50-53]. The two nonsynonymous polymorphisms, Try113His and His139Arg, are common in Caucasians as well as Asians. The allele frequency of Try 113 His $(337 \mathrm{~T}>\mathrm{G})$ is reported to be $22-31 \%$ in Caucasians and approximately $45 \%$ in Asians, and that of His139Arg (416A>G) is $20-22 \%$ in Caucasians and approximately $14 \%$ in Asians [54-56]. Early in vitro expression studies demonstrated that the Try 113 His variant confers a nearly $40 \%$ decrease in hydrolase activity, whereas the His 139 Arg variant confers an increase in activity of at least 25\% [49]. These variant alleles have also been reported to affect enzyme stability [57]. These polymorphisms in EPHX1 could therefore affect the pharmacokinetics of AEDs and the fetal exposure to the reactive oxide intermediates in pregnant women with these polymorphisms [45,58-61].

\subsection{Uridine diphospho-glucuronosyltransferase (UGT)}

UGT enzymes are key metabolic proteins that prevent the accumulation of potentially toxic lipophilic compounds and initiate their elimination through more the hydrophilic biliary and renal systems [62]. This is accomplished by the addition of a hydrophilic sugar moiety (glucuronide) from uridine diphosphate (UDP) glucuronic acid by UGTs [62]. The UGT enzymes have been classified into two major families in humans, namely UGT1A and UGT2 (subdivided into UGT2A and UGT2B) [62]. The influence of inheritable polymorphisms on human UGT-encoding genes has been extensively documented, and was shown to be responsible for a fraction of the observed phenotypic variability in metabolism and excretion [63].

Pathways involving members of the UGT1 superfamily act on approximately $35 \%$ of all drugs metabolized by phase II drug metabolizing enzymes [64], including several AEDs such as carbamazepine, valproic acid, lamotrigine, oxcarbazepine, topiramate and zonisamide [22,25]. One of the common genetic polymorphisms in UGT1A genes is a TA insertion in the UGT1A1 TATA-box, 41 nucleotides upstream of the translation start site, leading to the variant $(\mathrm{TA})_{7}$ allele (UGT1A1*28) instead of the $(\mathrm{TA})_{6}$ reference allele $(U G T 1 A 1 * 1)$. This $U G T 1 A 1$ promoter region dinucleotide repeat polymorphism results in reduced expression levels by altering transcription initiation, and also results in an approximately $70 \%$ reduction in glucuronidation of bilirubin and other UGT1A1 substrates 
$[65,66]$. A number of studies have shown that $U G T 1 A 1 * 28$ is relatively frequent in many populations, with an allele frequency $32-39 \%$ in Caucasians, $40-43 \%$ in Africans, and 16-18\% in Asians [65,66].

UGT2B7 also contributes to the glucuronidation of AEDs such as valproic acid, carbamazepine and lamotrigine [67-69]. Several polymorphisms have been identified within the UGT2B7 gene. The A to $\mathrm{T}$ transversion at nucleotide 802 leads to a change in amino acid sequence, His268Try. This allele is designated as $U G T 2 B 7 * 2$, and the frequency of the $U G T 2 B 7 * 2$ allele is 48.9 and $26.8 \%$ in Caucasians and Asians, respectively [70]. Variants have also been identified within the UGT2B7 promoter that exhibit some ethnic/race-dependent haplotype structures and seem to depend more on linkage to structural variants [53]. A haplotype defined by six promoter variants, involving $-901 \mathrm{G}>\mathrm{A}$ and $161 \mathrm{~T}>\mathrm{C}$, was observed at a frequency between 44 and 55\% in Caucasians and about 25\% in Asians [71-73]. Functional analysis of this haplotype in vitro revealed an approximate 2-fold increase in activity in both HepG2 hepatoma cells and CaCo-2 colon cells [71].

These genetic polymorphisms may affect the pharmacokinetics of AEDs, thereby altering their efficacy and adverse event profiles [23]. However, in most instances, the functional significance of these polymorphisms is unclear for a number of reasons; isozyme substrate specificity remains poorly defined, isoforms may exhibit overlapping substrate specificity, and the domains of UGT proteins responsible for substrate binding have not been identified [62,74].

\subsection{Glutathione S-transferase (GST)}

GST catalyzes the conjugation of glutathione (GSH) with electrophiles, generally resulting in their detoxification and facilitated elimination [75]. The ability to conjugate electrophiles makes these enzymes critical in the detoxification of a wide range of epoxides and certain other agents, including therapeutic drugs, pesticides and dietary components [76,77]. Since some AEDs are biotransformed to reactive oxides during their metabolism, GST is one of the key enzymes in the detoxification of these metabolites [78].

Polymorphisms that exert substantial effects on the GST function have been noted in human populations for several isozymes [78]. Monte Carlo simulations indicated large inter-individual variability for GSTM1 and T1 due to the presence of the null (zero activity) genotype, which is common in all populations studied [78]. The GSTM1 and GSTT1 genotypes have also been studied across wide variety of populations [78]. The GSTM1 null genotype is common, with frequencies of 40-60\% in Caucasians and Asians, and 20-25\% in African Americans [78]. The GSTT1 null genotype is less frequent than the GSTM1 null genotype in Caucasians (18\%) but has a similar frequency to the GSTM1 null genotype in Asian groups (generally ranging from 40-60\%) and in African Americans $(22 \%)$ [78]. Several studies also reported the double null genotype (GSTM1 null and GSTT1 null) with frequencies close to what is expected by assuming independent inheritance and thus simply multiplying the two null frequencies together. The double null frequency was reported to occur at frequency of $9.6 \%$ in Caucasians, $6 \%$ in African Americans, 20-33\% in Asians [78]. 


\section{Effect of Genetic Polymorphisms of Drug-Metabolizing Enzymes on AED Therapy}

\subsection{Carbamazepine}

Carbamazepine is extensively metabolized in the liver, with less than $5 \%$ of an oral dose excreted unchanged in urine [79]. Carbamazepine is predominantly metabolized by CYP3A4, and partially by CYP2C8, to carbamazepine-10,11-epoxide. Carbamazepine-10,11-epoxide is subsequently transformed by $\mathrm{mEH}$ to the inactive carbamazepine-10,11-diol, which is finally excreted into the urine in free and conjugated forms [80]. Carbamazepine-10,11-epoxide and carbamazepine-10,11-trans-diol are the primary $(\leq 60 \%)$ metabolites in urine $[81,82]$. Carbamazepine has a narrow therapeutic range between serum concentrations of $3-12 \mu \mathrm{g} / \mathrm{mL}[83]$.

\subsubsection{Pharmacokinetics}

In a recent study of 35 Korean patients treated with carbamazepine monotherapy, patients with the CYP3A5*3/*3 genotype showed $31 \%$ higher serum levels of carbamazepine compared to those with CYP3A5*1/*1 or $* 1 / * 3$ genotypes [44]. In addition, the oral clearance of carbamazepine in patients with the CYP3A5*3/*3 genotype was $29 \%$ lower than that of patients with the CYP3A5*1/*1 or CYP3A5*1/*3 genotype [44]. The influence of the CYP3A5 genotype on the population pharmacokinetics of carbamazepine were also assessed in 144 Japanese patients treated with carbamazepine polytherapy in combination with enzyme-inducing AEDs, phenytoin and phenobarbital, as well as with carbamazepine monotherapy $[12,43]$. In this study, the population clearance estimates for carbamazepine indicated that there was an $8 \%$ increase in the serum concentration in patients with CYP3A5*3/*3 compared to those with CYP3A5*1/*1 or *1/*3, suggesting that the CYP3A5*3 genotypes may not be as important in the pharmacokinetics of carbamazepine in Japanese patients with epilepsy. However, further studies are necessary to elucidate underlying mechanism of these findings in larger and different ethnic populations.

Several EPHX1 polymorphisms are associated with altered carbamazepine-10,11-epoxide metabolism [54]. The plasma carbamazepine-10,11-trans-diol to carbamazepine-10,11-epoxide ratios increased significantly, depending on the number of haplotype *2 bearing Try113His, whereas the ratios decreased in patients with His139Arg [54]. In a recent study of 70 patients with epilepsy in Scotland, a multivariate model incorporating patient age and EPHX1 Try113His and His139Arg polymorphisms, revealed a significant association between the genotypes and the maintenance dose of carbamazepine [84].

\subsubsection{Pharmacodynamics}

Cutaneous adverse drug reactions (cADR), ranging from a mild maculopapular exanthema to lifethreatening severe cutaneous reactions such as Stevens-Johnson syndrome, are among the most common adverse effects of AEDs [8]. The FDA issued an alert and updated product labeling recommending genetic testing for $H L A-B$ polymorphisms to predict carbamazepine-induced serious skin reactions in individuals of Asian descent [85]. In a search for genetically-determined abnormalities in carbamazepine metabolism in 91 Taiwanese patients, 278 single nucleotide polymorphisms, including CYP3A4, CYP1A2 and EPHX1, and the major histocompatibility complex 
region, tumor necrosis factor- $\alpha$ and heat shock protein, were screened [86]. Although an association between $H L A-B^{*} 1502$ and cADR was found, no polymorphisms involved in the metabolism of carbamazepine were identified as being pathogenic in these patients [86].

AEDs-related hepatotoxicity can be caused by immune-mediated mechanisms or direct cytotoxic damage [9,87]. A retrospective study in Japanese patients with epilepsy implicated the GSTM1 null genotype as a risk factor for carbamazepine-induced mild hepatotoxicity, whereas the EPHX1 polymorphisms did not lead to any elevation of transaminases in 192 Japanese patients treated with carbamazepine [88].

\subsection{Clobazam}

More than $70 \%$ of the administered dose of clobazam is demethylated to yield $N$-desmethylclobazam, a pharmacologically active metabolite that reaches higher plasma concentrations than clobazam and may substantially contribute to the efficacy and toxicity of long-term clobazam therapy [89,90]. This demethylation is facilitated by CYP3A4, CYP2C19 and CYP2B6, and the subsequent inactivation of $N$ desmethylclobazam to 4'-hydroxynorclobazam is catalyzed primarily by CYP2C19 [91]. There is little information about the target serum concentration of clobazam and $\mathrm{N}$-desmethylclobazam.

\subsubsection{Pharmacokinetics}

A recent study of 110 Japanese patients with epilepsy demonstrated that the mean serum concentration of $N$-desmethylclobazam was nine times higher in CYP2C19 PMs than in CYP2C19 homo EMs, and the degree of elevation in the serum $N$-desmethylclobazam/clobazam concentration ratio was dependent on the number of defective alleles of CYP2C19. This indicates that the CYP2C19 genotypes are associated with the serum concentration of the active metabolite of clobazam, $N$-desmethylclobazam [35].

\subsubsection{Pharmacodynamics}

In this same study [35], the responder rate was significantly greater in CYP2C19 PMs and CYP2C19 hetero EMs than in CYP2C19 homo EMs, with a gene-dose effect (65.2, 47.6 and 33.3\%, respectively), and the adjusted odds ratio (95\% confidence interval) of CYP2C19 PMs versus CYP2C19 homo EMs was 9.88 (2.47-39.56). The incidence adverse reactions, including drowsiness and dizziness, tended to be higher in CYP2C19 PMs (64.0\%) than in the CYP2C19 hetero EMs or CYP2C19 homo EMs (43.2 and 39.0\%, respectively, $P=0.07$ ) [35], and the incidence in the homo EMs was similar to those in Canadian or European studies [92-94]. The frequency of CYP2C19 PMs varies across races, for example, $13-23 \%$ of Asians and 1-8\% of Caucasians are estimated to be PMs [30,31]. Therefore, a variety of CYP2C19 polymorphisms may affect the incidence of the adverse effects of clobazam. On the other hand, the CYP2C19 genotypes were not associated with the tolerance. These results suggest that CYP2C19 polymorphisms are associated with the clinical efficacy of clobazam therapy, but that they are not associated with tolerance to the drug [35]. 


\subsection{Lamotrigine}

Lamotrigine undergoes glucuronidation on the 2-nitrogen atom of the triazine ring, leading to an inactive quaternary ammonium-linked $N$-2-glucuronide [95]. Lamotrigine is mainly metabolized by UGT1A4 [95], but other UGTs such as UGT1A1 and UGT2B7 contribute to lamotrigine glucuronidation $[69,96]$. Patients treated with therapeutic doses have serum lamotrigine concentrations in the order of $2.5-15 \mu \mathrm{g} / \mathrm{mL}[25]$.

\subsubsection{Pharmacokinetics}

A recent study of Spanish patients with epilepsy revealed that a significant association was found between the lamotrigine concentration and the dose (C/D) ratio and UGT2B7 -161C $>$ T polymorphisms, and co-medication with agents such as valproic acid and enzyme-inducing AEDs was responsible for most of the inter-individual variability in the lamotrigine $\mathrm{C} / \mathrm{D}$ ratio (70\%), followed by patient age (24\%) and the UGT2B7 -161C $>$ T polymorphism (12\%) [97].

\subsubsection{Pharmacodynamics}

To the best of our knowledge, no studies have been undertaken to examine whether genetic polymorphisms in UGT genes affect the efficacy or safety of lamotrigine therapy.

\subsection{Phenytoin}

Phenytoin exhibits a non-linear relationship between doses and serum concentrations, and the therapeutic window is narrow, with a range usually between 5 and $25 \mu \mathrm{g} / \mathrm{mL}$ [83]. Seventy to $90 \%$ of the oral administrated dose of phenytoin is oxidized, mainly by CYP2C9, and to a minor extent by CYP2C19, to yield S-5-(4p-hydroxyphenyl)-5-phenylhydantoin ( $p$-HPPH) in humans [98,99]. The relative contribution of $\mathrm{CYP} 2 \mathrm{C} 19$ to phenytoin metabolism increases as phenytoin concentrations increase, leading to saturation of CYP2C9 [99].

\subsubsection{Pharmacokinetics}

The CYP2C9*2, CYP2C9*3 and CYP2C19*2 alleles have all been shown to affect the phenytoin plasma concentration and toxicity [33,34,39,100-103]. Several studies of phenytoin have shown that genetic polymorphisms of CYP2C9 and CYP2C19 correlate with the dose needed by patients to control seizures $[33,34,39,100,101]$. In a retrospective analysis of 269 patients with epilepsy from the UK, the maximal dose of phenytoin was stratified according to the CYP2C9 genotypes of patients [39]. Carriers of one or two defective CYP2C9 alleles (i.e., CYP2C9 hetero EMs or PMs) apparently needed a 13\% and 30\% lower dose, respectively [39]. In another analysis of 169 patients with epilepsy from Taiwan, a clinically relevant decrease in the maximal rate of metabolism $\left(\mathrm{V}_{\max }\right)$ and intrinsic clearance was observed when the patients were CYP2C9 hetero EMs in combination with CYP2C19 hetero EMs or PMs [34]. Based on the calculated pharmacokinetic parameters, the authors recommended reducing the normal dosage of phenytoin (5-7 mg/kg/day) to $2-4 \mathrm{mg} / \mathrm{kg}$ /day for carriers of these genotypes [34]. 
Another recent study found that CYP2C19*2 was in complete linkage disequilibrium with $C Y P 2 C 9 * 1 B$, containing two genetic variants in the extended promoter of CYP2C9; the $-3089 \mathrm{G}>\mathrm{A}$ and -2663delTG polymorphisms in Caucasians [104]. Among patients who did not carry the CYP2C9*2 or *3 alleles, the CYP2C9*1B haplotype was significantly associated with a reduced phenytoin maintenance dose, consistent with reduced phenytoin induction of CYP2C9 metabolism in CYP2C9*1B carriers [104]. A multivariate model that includes all CYP2C9 genotype information in addition to gender, body weight, and genomic ancestry showed that nearly half of the variation in phenytoin maintenance dose can be explained by these predictors, with up to $10 \%$ of the variation in dose attributable to the CYP2C $9 * 1 B$ haplotype alone [104].

\subsubsection{Pharmacodynamics}

Several case studies reported that phenytoin-induced central nervous system toxicities were observed when the patients were carriers of defective CYP2C9 and/or CYP2C19 allele(s) [12,105-108]. Concerning the development of cADRs or gingival hyperplasia during phenytoin therapy, it is not yet clear whether there is an association with CYP2C9/2C19 polymorphisms [109-111]. A previous review article suggested that individual pharmacogenetic differences in CYP2C9 and EPHX1 may increase susceptibility to birth defects after fetal exposure to phenytoin [61]. Recently, the risk of phenytoin-induced craniofacial abnormalities in children was assessed in relation to known maternal functional polymorphisms of CYP2C9 and EPHX1 in the Collaborative Perinatal Project database [58]. The risk in the child was lower for the maternal EPHX1 113Try/139His haplotype than in other EPHX1 haplotypes (odds ratio $=0.29$ ), whereas the CYP2C9 genotype was not related to any of the fetal endpoints assessed [58].

\subsection{Phenobarbital}

Phenobarbital is eliminated by a combination of renal excretion of the unchanged drug (25\%), $N$ glucoside formation (25\%) and CYP2C9- and/or CYP2C19-dependent oxidation ( $\leq 25 \%)$ [112,113]. However, independent data showing a substantial contribution of these CYPs on phenobarbital metabolism are currently missing. In patients treated with therapeutic doses, serum phenobarbital concentrations in the order of $10-40 \mu \mathrm{g} / \mathrm{mL}$ have been reported [83].

\subsubsection{Pharmacokinetics}

The clearance of phenobarbital was shown to be 18.8\% lower in CYP2C19 PMs, compared to other CYP2C19 genotypes, in 74 Japanese patients with epilepsy [114], in which carriers of the defective CYP2C9 allele(s) were excluded. The influences of the CYP2C9 and CYP2C19 genotypes on the population clearance estimates for phenobarbital were also evaluated in 79 Japanese patients with epilepsy [12,36]. The phenobarbital clearance in patients with the CYP2C9 hetero EMs was $48 \%$ lower than in those with the homo EMs $(P<0.001)$, whereas no effect of the CYP2C19 genotype on the phenobarbital clearance was observed [12,36]. 


\subsubsection{Pharmacodynamics}

Individuals with reduced CYP2C9 activity, carriers of one or two defective CYP2C9 allele(s), are more prevalent in Caucasians (35\%) than in African-Americans (13\%) and Asians (3.5\%) [30,31]. The incidences of phenobarbital-related adverse reactions were reported to be higher in Caucasians (22-60\%) than in African-Americans (3.2\%) and Asians (1\%) [115-118]. The lower frequency of the individuals with reduced CYP2C9 activity among Asians and African-Americans might be a possible explanation for the higher tolerability of phenobarbital in these races compared to Caucasians $[12,36]$.

\subsection{Valproic acid}

Valproic acid shows high inter-individual variability in pharmacokinetics and pharmacodynamics and has a narrow therapeutic range; therefore, its plasma level needs to be carefully monitored during the course of therapy $(50-100 \mu \mathrm{g} / \mathrm{mL})$ [119]. The major metabolic pathways of valproic acid comprise glucuronidation, $\beta$-oxidation and $\omega$-oxidation.

\subsubsection{Pharmacokinetics}

A recent population pharmacokinetic study in 287 Chinese patients with epilepsy showed that CYP2C9 in combination with CYP2C19 genotypes significantly influenced the pharmacokinetic variability of valproic acid, as quantified by population pharmacokinetic analysis [120]. UGT2B7 also contributes to the glucuronidation of valproic acid [68,121]. A notable but non-significant tendency toward an increase in the area under the curve of serum concentrations of valproic acid was found as the number of $U G T 2 B 7 * 2$ alleles increased [67].

\subsubsection{Pharmacodynamics}

Valproic acid has a direct toxic action, and susceptibility to valproic acid-induced hepatotoxicity may be enhanced by alterations in the metabolism of valproic acid [9]. It has been known for a long time that, in rare cases, valproic acid can cause liver damage, which is partially due to the CYPcatalyzed formation of the hepatotoxic metabolite, 4-ene-valproic acid [122]. From in vitro studies, it was concluded that CYP2C9 mediates the metabolic conversion of valproic acid to form 4-ene-valproic acid [123]. However, it remains unresolved as to whether CYP2C9 polymorphisms could be responsible for the hepatotoxic potential to valproic acid. As valproic acid can cause oxidative stress in rats, which precedes the onset of hepatotoxicity, a CYP-independent mechanism might also be in effect [124]. An association between the common polymorphisms in the GSTM1 and GSTT1 null genes and an increase of $\gamma$-glutamyltransferase, which was proposed to be a surrogate marker for mild hepatotoxicity in the study, was reported in 149 valproic acid-treated Japanese patients with epilepsy [125].

\subsection{Zonisamide}

Zonisamide is eliminated via renal excretion of the 2-sulfamoylacetyl-phenol-glucuronide (SMAP) (50\%), of the unchanged form (35\%) and of $N$-acetyl zonisamide (15\%) [126,127]. The formation of SMAP is catalyzed mainly by CYP3A4, and to a minor extent by CYP3A5 and CYP2C19, as shown in 
an in vitro study [128]. A range of 10 and $38 \mu \mathrm{g} / \mathrm{mL}$ in serum has been reported in patients treated with therapeutic doses [25].

\subsubsection{Pharmacokinetics}

The influence of CYP2C19 and CYP3A5 genotypes on the population clearance estimates of zonisamide were assessed in 99 Japanese patients with epilepsy [12,38]. The zonisamide clearance in CYP2C19 hetero EMs and PMs was 16\% and 30\% lower than in homo EMs, respectively. A genedose effect was observed for the number of defective CYP2C19 allele(s), which lends further credence to the involvement of CYP2C19 in the metabolism of zonisamide in patients $[12,129]$. Conversely, the CYP3A5*3 genotype did not affect the clearance of zonisamide, indicating that the CYP3A5*3 genotypes do not contribute significantly to the zonisamide pharmacokinetics in Japanese patients with epilepsy $[12,129]$.

\subsubsection{Pharmacodynamics}

We verified the clinical impact of the CYP2C19 genotype on the effects of zonisamide therapy in 99 Japanese patients as cited above [12]. The median concentration to dose ratios of zonisamide in PMs tended to be higher than in homo EMs [12]. Two out of 27 PMs (7.4\%) and 5 out of 79 hetero EMs (6.3\%), but none of the 64 homo EMs $(0 \%)$, developed zonisamide-specific adverse reactions, fever and/or hypohidrosis [12].

\section{Population Pharmacokinetics of AEDs}

The mixed-effect population pharmacokinetic approach permits study of the sources and correlates of variability in blood concentrations between individuals [130]. Because the population pharmacokinetic approach is the optimal methodology for indentifying the magnitude of the effect of the putative factors affecting the variation in pharmacokinetics in patients, a population pharmacokinetic approach makes it possible to determine the dosing regimen to achieve plasma concentrations within a given target range. Moreover, compared with the traditional pharmacokinetic methods, population pharmacokinetics is better suited for analyzing large-scale clinical studies, where only a few samples are available per subject or patient. Table 2 summarizes the evidence for genetic polymorphisms of drug-metabolizing enzymes associated with the population pharmacokinetic model of AEDs.

As described, we evaluated the associations between the genotypes of CYP2C9, CYP2C19 and/or CYP3A5 and population clearance estimates of AEDs such as carbamazepine, phenobarbital and zonisamide (Table 2) [12,36-38,43]. For example, the phenobarbital clearance in CYP2C9 hetero EMs was $48 \%$ lower than in homo EMs (Table 2) [12,36]. Valproic acid, a known inhibitor of phenobarbital metabolism, and phenytoin, a substrate of CYP2C9 and CYP2C19, were also incorporated into the PPK models (Table 2). Although the CYP2C19 genotypes were shown to affect the population clearance estimates of phenobarbital in Japanese patients in a previous study [37,114] in which carriers of the defective CYP2C9 allele(s) were excluded, we observed no effect of the CYP2C19 genotype on phenobarbital clearance $(P>0.05)$ (Table 2$)$. It should be noted that the number of CYP2C9 hetero 
EMs was small ( $\mathrm{n}=10$ in total), and the effects of CYP2C9 genotypes on the pharmacokinetics of phenobarbital were model-based, and hence the proof of their involvement was indirect $[12,36]$. However, these results suggest that the CYP2C9 genotypes may play an important role in the pharmacokinetics of phenobarbital in Japanese patients with epilepsy, and might affect the ethnic differences in the tolerability of phenobarbital therapy (see section 5.5) [12,36].

Table 2. The population pharmacokinetic model of antiepileptic drugs incorporating the drug-metabolizing enzyme polymorphisms.

\begin{tabular}{|c|c|c|c|}
\hline AED & Final population pharmacokinetic model & Population & Ref. \\
\hline Carbamazepine & $\begin{array}{c}\mathrm{CL}(\mathrm{l} / \mathrm{h})=0.17 \times(\mathrm{BW} / 40)^{0.11} \times \mathrm{Dose}^{0.45} \times \\
1.40^{\mathrm{PHT}} \times 1.21^{\mathrm{PB}} \times 1.08^{\mathrm{CYP} 3 A 5^{*} 3 / * 3} \times \mathrm{e}^{\eta \mathrm{CL}}\end{array}$ & Japanese & {$[12,43]$} \\
\hline Phenobarbital & $\begin{array}{l}\mathrm{CL}(\mathrm{l} / \mathrm{h})=0.23 \times(\mathrm{BW} / 40)^{0.21} \times 0.52^{\mathrm{CYP} 2 \mathrm{C} 9 \text { hetero EM }} \\
\quad \times 0.68^{\mathrm{VPA}} \times 0.85^{\mathrm{PHT}} \times 0.85^{\mathrm{SMID}} \times(1+\eta \mathrm{CL})\end{array}$ & Japanese & {$[12,36]$} \\
\hline \multirow{3}{*}{ Phenytoin } & $\mathrm{CL}(1 / \mathrm{h})=0.0596 \times \mathrm{BW}^{0.367} \times 0.812^{\mathrm{CYP2C19} \mathrm{PM}}$ & Japanese & {$[37,114]$} \\
\hline & $\begin{array}{c}\mathrm{V}_{\max }(\mathrm{mg} / \mathrm{day} / \mathrm{kg})=6.07 \times(\mathrm{BW} / 60)^{-0.416} \times \\
0.582^{\text {CYP2C9 hetero } \mathrm{EM}} \times\left(1+\eta \mathrm{V}_{\max }\right)\end{array}$ & \multirow[t]{2}{*}{ Japanese } & \multirow[t]{2}{*}[33]{} \\
\hline & $\begin{array}{c}\mathrm{K}_{\mathrm{m}}(\mu \mathrm{g} / \mathrm{mL})=4.0 \times 1.22^{\text {CYP2C19 hetero EM }} \times \\
1.54^{\text {CYP2C19 PM }} \times\left(1+\eta \mathrm{K}_{\mathrm{m}}\right)\end{array}$ & & \\
\hline Valproic acid & $\begin{array}{l}\mathrm{CL}(1 / \mathrm{h})=0.0951 \times\left(1+\mathrm{e}^{0.0267 \times(3-\mathrm{G} \dagger)}\right) \times 0.0071 \times \\
\quad \text { age } \times \mathrm{e}^{\eta \mathrm{\eta L}}\end{array}$ & Chinese & {$[120]$} \\
\hline Zonisamide & $\begin{array}{l}\mathrm{CL}(\mathrm{l} / \mathrm{h})=1.22 \times(\mathrm{BW} / 44)^{0.77} \times \operatorname{Dose}^{-0.17} \times \\
\quad 0.84^{\text {CYP2C19 hetero EM }} \times 0.70^{\text {CYP2C19 PM }} \times 1.24^{\mathrm{CBZ}} \\
\quad \times 1.28^{\mathrm{PHT}} \times 1.29^{\mathrm{PB}} \times \mathrm{e}^{\eta \mathrm{CL}}\end{array}$ & Japanese & {$[12,38]$} \\
\hline
\end{tabular}

AED, antiepileptic drug; $\mathrm{V}_{\max }$, maximal elimination rate; $\mathrm{K}_{\mathrm{m}}$, Michaelis-Menten constants; $\mathrm{CL}$, apparent clearance; BW, body weight; Dose, daily dose of each antiepileptic drug; Homo EM, homozygous extensive metabolizers; Hetero EM, heterozygous extensive metabolizers; PM, poor metabolizers; CYP2C9 hetero $\mathrm{EM}=1$, CYP2C9 homo EM = 0; CYP2C19 hetero EM or CYP2C19 PM = 1 if one or two CYP2C19defective alleles are carried, respectively, otherwise $0 ; C Y P 3 A 5 * 3 / * 3=1$, otherwise $0 ; \mathrm{VPA}=1$ if valproic acid is co-administered, otherwise 0 ; PHT $=1$ if phenytoin is co-administered, otherwise 0 ; CBZ $=1$ if carbamazepine is co-administered, otherwise $0 ; \mathrm{PB}=1$ if phenobarbital is co-administered, otherwise 0 ; SMID $=1$ if complications of severe or profound mental retardation with significant behavior impairment are presented, otherwise 0 ; and $\eta=$ the independent random error distributed normally with the mean zero. ${ }^{\dagger} \mathrm{G}$ was 1, 2, and 3, where the genotype was wild type (CYP2C19*1/*1 combined with CYP2C9*1/*1), heterozygous (CYP2C19*1/*2 or CYP2C19*1/*3), and homozygous genotypes (CYP2C19*2/*2 or CYP2C19*2/3 or CYP2C19*3/*3 combined with CYP2C9*1/*3), respectively.

Meanwhile, the population clearance estimate of zonisamide in CYP2C19 hetero EMs and PMs was $16 \%$ and $30 \%$, respectively, lower than in homo EMs (Table 2) [12,38]. A gene-dose effect was observed for the number of defective CYP2C19 allele(s), which lends further credence to the involvement of CYP2C19 in zonisamide metabolism in patients [12,38]. Enzyme-inducing AEDs such as carbamazepine, phenytoin and phenobarbital were also incorporated into the population 
pharmacokinetic models (Table 2). In contrast to CYP2C19, the CYP3A5*3 genotype did not affect the clearance of zonisamide, indicating that CYP3A5*3 genotypes do not have a major impact on the zonisamide pharmacokinetics in Japanese patients with epilepsy. Therefore, the CYP2C19 genotypes may play an important role in the pharmacokinetics of zonisamide and may affect the development of adverse reactions (see section 5.7) [12,38].

These findings suggest that the population pharmacokinetic approach enables us to define relevant genetic factors, together with other non-genetic factors, and to estimate the magnitude of their effects on the variation in pharmacokinetics in patients. Additionally, although the co-expression of drugmetabolizing enzymes and transporters should also be considered [130], population pharmacokinetic modeling in patients can be used to assess the contribution of drug-metabolizing enzymes on the metabolisms of AEDs, and to predict the AED-induced adverse reactions.

Table 3. The clinical impact of genetic polymorphisms of drug-metabolizing enzymes on AED therapy.

\begin{tabular}{|c|c|c|c|}
\hline AED & Genetic polymorphisms & $\begin{array}{l}\text { Associated pharmacokinetic or } \\
\text { pharmacodynamic parameters }\end{array}$ & References \\
\hline \multirow[t]{3}{*}{ Carbamazepine } & CYP $3 A 5 * 3 / * 3$ genotype & Oral clearance & {$[12,43,44]$} \\
\hline & $\begin{array}{l}\text { EPHX1 Try } 113 \text { His and } \\
\text { His139Arg }\end{array}$ & Maintenance dose & {$[84]$} \\
\hline & GSTM1 null genotype & Mild hepatotoxicity & {$[88]$} \\
\hline Clobazam & $\begin{array}{l}\text { CYP2C19 hetero EMs and } \\
\text { PMs }\end{array}$ & $\begin{array}{l}\text { Serum } N \text {-desmethylclobazam } \\
\text { concentration, responder rate }\end{array}$ & {$[35]$} \\
\hline Lamotrigine & UGT2B7 $-161 \mathrm{C}>\mathrm{T}$ & Concentration to daily dose ratio & [97] \\
\hline \multirow[t]{2}{*}{ Phenobarbital } & CYP2C19 PMs & Oral clearance & [37] \\
\hline & CYP2C9 hetero EMs & $\begin{array}{l}\text { Oral clearance, ethnic differences in } \\
\text { tolerability (?) }\end{array}$ & {$[12,36]$} \\
\hline \multirow[t]{3}{*}{ Phenytoin } & $\begin{array}{l}\text { CYP2C9 hetero EMs/PMs } \\
\text { and/or CYP2C19 PMs }\end{array}$ & $\begin{array}{l}\text { Plasma concentration, maintenance dose, } \\
\text { CNS toxicity }\end{array}$ & {$[12]$} \\
\hline & CYP2C9*1B haplotype & Maintenance dose & [104] \\
\hline & $\begin{array}{l}\text { EPHX1 113Try/139His } \\
\text { haplotype }\end{array}$ & Risk of craniofacial abnormalities & {$[58]$} \\
\hline \multirow[t]{2}{*}{ Valproic acid } & $\begin{array}{l}\text { CYP2C9 hetero EMs and } \\
\text { CYP2C19 PMs }\end{array}$ & Oral clearance & [120] \\
\hline & $\begin{array}{l}\text { GSTM1 and GSTT1 null } \\
\text { genotypes }\end{array}$ & Mild elevation of $\gamma$-glutamyltransferase & [125] \\
\hline Zonisamide & $\begin{array}{l}\text { CYP2C19 hetero EMs and } \\
\text { PMs }\end{array}$ & $\begin{array}{l}\text { Oral clearance, zonisamide-specific } \\
\text { adverse reactions }\end{array}$ & {$[12,38]$} \\
\hline
\end{tabular}

AED, antiepileptic drug; CYP, cytochrome P450; EPHX1, microsomal epoxide hydrolase gene; UGT, UDP-glucuronosyltransferase; GST, Glutathione S-transferase; CNS, central nervous system. 


\section{Conclusions and Future Perspectives}

In conclusion, the recent findings indicate that genetic polymorphisms of drug-metabolizing enzymes may have a clinical impact on AED therapy (Table 3). However, at present, screening for these polymorphisms requires intensive genotyping to determine a patient's optimal dose of AED. Such studies to generate personalized AED therapy are currently quite laborious [7,10]. There are several explanation for the slow progress being made in clinical pharmacogenetics; the most important of which is the fact that gene function is not a constant, but varies depending on environmental factors and the respective gene products themselves [131-133]. Another essential problem is the lack of prospective clinical studies assessing the merit of genotyping strategies for AED therapy in large numbers of patients. Therefore, it would be helpful to implement more clinical integration of pharmacogenetic information includings (1) the prospective associations between genetic polymorphisms and the clinical endpoints in the large population; (2) replication of observed associations; (3) studies including various ethnic groups; (4) careful analysis of confounding factors, such as drug-drug interactions and population stratification, and (5) analysis of combinations of genetic polymorphisms of transporters affecting the AED exposure (e.g., organic cation transporter 1 polymorphisms [134]), and other genetic factors affecting the enzyme activity (e.g., transcriptional nuclear factors). The use of population pharmacokinetic modeling incorporating the genotypes of drugmetabolizing enzymes can be one of the most useful tools that can be used to facilitate the determination of individualized dosing regimens in AED therapy, and genetic and non-genetic factors affecting enzyme activity can be used reliably under such models by clinicians in selecting the best $\operatorname{AED}(s)$ and dose-adjustment for their patients.

\section{Acknowledgements}

This work was supported by Grant-in-aids (19590539, 16109006 and 22790161) for scientific research from the Japanese Ministry of Education, Science, Sports and Culture. We thank Naoki Ogusu for assistance in the collection and review of the published articles.

\section{References}

1. Duncan, J.S.; Sander, J.W.; Sisodiya, S.M.; Walker, M.C. Adult epilepsy. Lancet 2006, 367, 1087-1100.

2. Guerrini, R. Epilepsy in children. Lancet 2006, 367, 499-524.

3. Arain, A.M.; Abou-Khalil, B.W. Management of new-onset epilepsy in the elderly. Nat. Rev. Neurol. 2009, 5, 363-371.

4. Sillanpaa, M.; Schmidt, D. Natural history of treated childhood-onset epilepsy: prospective, longterm population-based study. Brain 2006, 129, 617-624.

5. Sisodiya, S.M.; Marini, C. Genetics of antiepileptic drug resistance. Curr. Opin. Neurol. 2009, 22 , $150-156$.

6. Kaneko, S.; Yoshida, S.; Kanai, K.; Yasui-Furukori, N.; Iwasa, H. Development of individualized medicine for epilepsy based on genetic information. Expert Rev. Clin. Pharmacol. 2008, 1, 661-681. 
7. Loscher, W.; Klotz, U.; Zimprich, F.; Schmidt, D. The clinical impact of pharmacogenetics on the treatment of epilepsy. Epilepsia 2009, 50, 1-23.

8. Franciotta, D.; Kwan, P.; Perucca, E. Genetic basis for idiosyncratic reactions to antiepileptic drugs. Curr. Opin. Neurol. 2009, 22, 144-149.

9. Kasperaviciute, D.; Sisodiya, S.M. Epilepsy pharmacogenetics. Pharmacogenomics 2009, 10, 817-836.

10. Tomalik-Scharte, D.; Lazar, A.; Fuhr, U.; Kirchheiner, J. The clinical role of genetic polymorphisms in drug-metabolizing enzymes. Pharmacogenomics J. 2008, 8, 4-15.

11. Anderson, G.D. Pharmacokinetic, pharmacodynamic, and pharmacogenetic targeted therapy of antiepileptic drugs. Ther. Drug Monit. 2008, 30, 173-180.

12. Saruwatari, J.; Ishitsu, T.; Seo, T.; Shimomasuda, M.; Okada, Y.; Goto, S.; Nagata, R.; Takashima, A.; Yoshida, S.; Yoshida, S.; Yasui-Furukori, N.; Kaneko, S.; Nakagawa, K. The clinical impact of cytochrome P450 polymorphisms on the anti-epileptic drug therapy. Epilepsy Seizure 2010, 3, 34-50.

13. Bhathena, A.; Spear, B.B. Pharmacogenetics: improving drug and dose selection. Curr. Opin. Pharmacol. 2008, 8, 639-646.

14. Katz, D.A.; Murray, B.; Bhathena, A.; Sahelijo, L. Defining drug disposition determinants: a pharmacogenetic-pharmacokinetic strategy. Nat. Rev. Drug Discov. 2008, 7, 293-305.

15. Flockhart, D.A.; Skaar, T.; Berlin, D.S.; Klein, T.E.; Nguyen, A.T. Clinically available pharmacogenomics tests. Clin. Pharmacol. Ther. 2009, 86, 109-113.

16. Ashley, E.A.; Butte, A.J.; Wheeler, M.T.; Chen, R.; Klein, T.E.; Dewey, F.E.; Dudley, J.T.; Ormond, K.E.; Pavlovic, A.; Morgan, A.A.; Pushkarev, D.; et al. Clinical assessment incorporating a personal genome. Lancet 2010, 375, 1525-1535.

17. Szoeke, C.E.; Newton, M.; Wood, J.M.; Goldstein, D.; Berkovic, S.F.; TJ, O.B.; Sheffield, L.J. Update on pharmacogenetics in epilepsy: a brief review. Lancet Neurol. 2006, 5, 189-196.

18. Klotz, U. The role of pharmacogenetics in the metabolism of antiepileptic drugs: pharmacokinetic and therapeutic implications. Clin. Pharmacokinet. 2007, 46, 271-279.

19. Anderson, G.D. Pharmacokinetic, pharmacodynamic, and pharmacogenetic targeted therapy of antiepileptic drugs. Ther. Drug Monit. 2008, 30, 173-180.

20. Sisodiya, S.M.; Marini, C. Genetics of antiepileptic drug resistance. Curr. Opin. Neurol. 2009, 22, 150-156.

21. Mann, M.W.; Pons, G. Various pharmacogenetic aspects of antiepileptic drug therapy: a review. CNS Drugs 2007, 21, 143-164.

22. Klotz, U. The role of pharmacogenetics in the metabolism of antiepileptic drugs: pharmacokinetic and therapeutic implications. Clin. Pharmacokinet. 2007, 46, 271-279.

23. Szoeke, C.E.; Newton, M.; Wood, J.M.; Goldstein, D.; Berkovic, S.F.; TJ, O.B.; Sheffield, L.J. Update on pharmacogenetics in epilepsy: a brief review. Lancet Neurol. 2006, 5, 189-196.

24. Johannessen, S.I.; Tomson, T. General principles. Laboratory monitoring of antiepleptic drugs. In Antiepileptic Drugs, 5th ed.; Levy, R. M., Mattson, R. H., Meldrum, B. S., Eds.; Lippincott Williams \& Wilkins: Philadelphia (PA), USA, 2002; pp. 103-111.

25. Johannessen, S.I.; Tomson, T. Pharmacokinetic variability of newer antiepileptic drugs: when is monitoring needed? Clin. Pharmacokinet. 2006, 45, 1061-1075. 
26. Diaz, R.A.; Sancho, J.; Serratosa, J. Antiepileptic drug interactions. Neurologist 2008, 14, 55-65.

27. Bhathena, A.; Spear, B.B. Pharmacogenetics: improving drug and dose selection. Curr. Opin. Pharmacol. 2008, 8, 639-646.

28. Katz, D.A.; Murray, B.; Bhathena, A.; Sahelijo, L. Defining drug disposition determinants: a pharmacogenetic-pharmacokinetic strategy. Nat. Rev. Drug Discov. 2008, 7, 293-305.

29. Flockhart, D.A.; Skaar, T.; Berlin, D.S.; Klein, T.E.; Nguyen, A.T. Clinically available pharmacogenomics tests. Clin. Pharmacol. Ther. 2009, 86, 109-113.

30. Myrand, S.P.; Sekiguchi, K.; Man, M.Z.; Lin, X.; Tzeng, R.Y.; Teng, C.H.; Hee, B.; Garrett, M.; Kikkawa, H.; Lin, C.Y.; et al. Pharmacokinetics/genotype associations for major cytochrome P450 enzymes in native and first- and third-generation Japanese populations: comparison with Korean, Chinese, and Caucasian populations. Clin. Pharmacol. Ther. 2008, 84, 347-361.

31. Makeeva, O.; Stepanov, V.; Puzyrev, V.; Goldstein, D.B.; Grossman, I. Global pharmacogenetics: genetic substructure of Eurasian populations and its effect on variants of drug-metabolizing enzymes. Pharmacogenomics 2008, 9, 847-868.

32. Yasui-Furukori, N.; Kaneda, A.; Iwashima, K.; Saito, M.; Nakagami, T.; Tsuchimine, S.; Kaneko, S. Association between cytochrome P450 (CYP) 2C19 polymorphisms and harm avoidance in Japanese. Am. J. Med. Genet. B Neuropsychiatr. Genet. 2007, 144B, 724-727.

33. Mamiya, K.; Ieiri, I.; Shimamoto, J.; Yukawa, E.; Imai, J.; Ninomiya, H.; Yamada, H.; Otsubo, K.; Higuchi, S.; Tashiro, N. The effects of genetic polymorphisms of CYP2C9 and CYP2C19 on phenytoin metabolism in Japanese adult patients with epilepsy: studies in stereoselective hydroxylation and population pharmacokinetics. Epilepsia 1998, 39, 1317-1323.

34. Hung, C.C.; Lin, C.J.; Chen, C.C.; Chang, C.J.; Liou, H.H. Dosage recommendation of phenytoin for patients with epilepsy with different CYP2C9/CYP2C19 polymorphisms. Ther. Drug Monit. 2004, 26, 534-540.

35. Seo, T.; Nagata, R.; Ishitsu, T.; Murata, T.; Takaishi, C.; Hori, M.; Nakagawa, K. Impact of CYP2C19 polymorphisms on the efficacy of clobazam therapy. Pharmacogenomics 2008, 9, 527-537.

36. Goto, S.; Seo, T.; Murata, T.; Nakada, N.; Ueda, N.; Ishitsu, T.; Nakagawa, K. Population estimation of the effects of cytochrome P450 2C9 and 2C19 polymorphisms on phenobarbital clearance in Japanese. Ther. Drug Monit. 2007, 29, 118-121.

37. Yukawa, E.; Mamiya, K. Effect of CYP2C19 genetic polymorphism on pharmacokinetics of phenytoin and phenobarbital in Japanese epileptic patients using Non-linear Mixed Effects Model approach. J. Clin. Pharm. Ther. 2006, 31, 275-282.

38. Okada, Y.; Seo, T.; Ishitsu, T.; Wanibuchi, A.; Hashimoto, N.; Higa, Y.; Nakagawa, K. Population estimation regarding the effects of cytochrome P450 2C19 and 3A5 polymorphisms on zonisamide clearance. Ther. Drug Monit. 2008, 30, 540-543.

39. Tate, S.K.; Depondt, C.; Sisodiya, S.M.; Cavalleri, G.L.; Schorge, S.; Soranzo, N.; Thom, M.; Sen, A.; Shorvon, S.D.; Sander, J.W.; Wood, N.W.; Goldstein, D.B. Genetic predictors of the maximum doses patients receive during clinical use of the anti-epileptic drugs carbamazepine and phenytoin. Proc. Natl. Acad. Sci. USA 2005, 102, 5507-5512. 
40. Kuehl, P.; Zhang, J.; Lin, Y.; Lamba, J.; Assem, M.; Schuetz, J.; Watkins, P.B.; Daly, A.; Wrighton, S.A.; Hall, S.D.; Maurel, P.; Relling, M.; Brimer, C.; Yasuda, K.; Venkataramanan, R.; Strom, S.; Thummel, K.; Boguski, M.S.; Schuetz, E. Sequence diversity in CYP3A promoters and characterization of the genetic basis of polymorphic CYP3A5 expression. Nat. Genet. 2001, 27, 383-391.

41. Lin, Y.S.; Dowling, A.L.; Quigley, S.D.; Farin, F.M.; Zhang, J.; Lamba, J.; Schuetz, E.G.,; Thummel, K.E. Co-regulation of CYP3A4 and CYP3A5 and contribution to hepatic and intestinal midazolam metabolism. Mol. Pharmacol. 2002, 62, 162-172.

42. Yamaori, S.; Yamazaki, H.; Iwano, S.; Kiyotani, K.; Matsumura, K.; Honda, G.; Nakagawa, K.; Ishizaki, T.; Kamataki, T. CYP3A5 Contributes significantly to CYP3A-mediated drug oxidations in liver microsomes from Japanese subjects. Drug Metab. Pharmacokinet. 2004, 19, 120-129.

43. Seo, T.; Nakada, N.; Ueda, N.; Hagiwara, T.; Hashimoto, N.; Nakagawa, K.; Ishitsu, T. Effect of CYP3A5*3 on carbamazepine pharmacokinetics in Japanese patients with epilepsy. Clin. Pharmacol. Ther. 2006, 79, 509-510.

44. Park, P.W.; Seo, Y.H.; Ahn, J.Y.; Kim, K.A.; Park, J.Y. Effect of CYP3A5*3 genotype on serum carbamazepine concentrations at steady-state in Korean epileptic patients. J. Clin. Pharm. Ther. 2009, 34, 569-574.

45. Decker, M.; Arand, M.; Cronin, A. Mammalian epoxide hydrolases in xenobiotic metabolism and signalling. Arch. Toxicol. 2009, 83, 297-318.

46. Oesch, F.; Glatt, H.; Schmassmann, H. The apparent ubiquity of epoxide hydratase in rat organs. Biochem. Pharmacol. 1977, 26, 603-607.

47. Seidegard, J.; DePierre, J.W. Microsomal epoxide hydrolase. Properties, regulation and function. Biochim. Biophys. Acta 1983, 695, 251-270.

48. Omiecinski, C.J.; Aicher, L.; Holubkov, R.; Checkoway, H. Human peripheral lymphocytes as indicators of microsomal epoxide hydrolase activity in liver and lung. Pharmacogenetics 1993, 3, $150-158$.

49. Hassett, C.; Lin, J.; Carty, C.L.; Laurenzana, E.M.; Omiecinski, C.J. Human hepatic microsomal epoxide hydrolase: comparative analysis of polymorphic expression. Arch. Biochem. Biophys. 1997, 337, 275-283.

50. Hassett, C.; Aicher, L.; Sidhu, J.S.; Omiecinski, C.J. Human microsomal epoxide hydrolase: genetic polymorphism and functional expression in vitro of amino acid variants. Hum. Mol. Genet. 1994, 3, 421-428.

51. Omiecinski, C.J.; Hassett, C.; Hosagrahara, V. Epoxide hydrolase-polymorphism and role in toxicology. Toxicol. Lett. 2000, 112-113, 365-370.

52. Saito, S.; Iida, A.; Sekine, A.; Eguchi, C.; Miura, Y.; Nakamura, Y. Seventy genetic variations in human microsomal and soluble epoxide hydrolase genes (EPHX1 and EPHX2) in the Japanese population. J. Hum. Genet. 2001, 46, 325-329.

53. Hines, R.N.; Koukouritaki, S.B.; Poch, M.T.; Stephens, M.C. Regulatory polymorphisms and their contribution to interindividual differences in the expression of enzymes influencing drug and toxicant disposition. Drug Metab. Rev. 2008, 40, 263-301. 
54. Nakajima, Y.; Saito, Y.; Shiseki, K.; Fukushima-Uesaka, H.; Hasegawa, R.; Ozawa, S.; Sugai, K.; Katoh, M.; Saitoh, O.; Ohnuma, T.; Kawai, M.; Ohtsuki, T.; Suzuki, C.; Minami, N.; Kimura, H.; Goto, Y.; Kamatani, N.; Kaniwa, N.; Sawada, J. Haplotype structures of EPHX1 and their effects on the metabolism of carbamazepine-10,11-epoxide in Japanese epileptic patients. Eur. J. Clin. Pharmacol. 2005, 61, 25-34.

55. Lacko, M.; Roelofs, H.M.; Te Morsche, R.H.; Voogd, A.C.; Oude Ophuis, M.B.; Peters, W.H.; Manni, J.J. Microsomal epoxide hydrolase genotypes and the risk for head and neck cancer. Head Neck 2008, 30, 836-844.

56. Graziano, C.; Comin, C.E.; Crisci, C.; Novelli, L.; Politi, L.; Messerini, L.; Andreani, M.; Porfirio, B. Functional polymorphisms of the microsomal epoxide hydrolase gene: a reappraisal on a early-onset lung cancer patients series. Lung Cancer 2009, 63, 187-193.

57. Laurenzana, E.M.; Hassett, C.; Omiecinski, C.J. Post-transcriptional regulation of human microsomal epoxide hydrolase. Pharmacogenetics 1998, 8, 157-167.

58. Azzato, E.M.; Chen, R.A.; Wacholder, S.; Chanock, S.J.; Klebanoff, M.A.; Caporaso, N.E. Maternal EPHX1 polymorphisms and risk of phenytoin-induced congenital malformations. Pharmacogenet. Genomics 2010, 20, 58-63.

59. Bellucci, G.; Berti, G.; Chiappe, C.; Lippi, A.; Marioni, F. The metabolism of carbamazepine in humans: steric course of the enzymatic hydrolysis of the 10,11-epoxide. J. Med. Chem. 1987, 30, 768-773.

60. Dennery, P.A. Effects of oxidative stress on embryonic development. Birth Defects Res. C. Embryol. Today 2007, 81, 155-162.

61. Van Dyke, D.C.; Berg, M.J.; Olson, C.H. Differences in phenytoin biotransformation and susceptibility to congenital malformations: a review. DICP 1991, 25, 987-992.

62. Guillemette, C.; Levesque, E.; Harvey, M.; Bellemare, J.; Menard, V. UGT genomic diversity: beyond gene duplication. Drug Metab. Rev. 2010, 42, 22-42.

63. UGT Nomenclature Commitee. UDP-glucuronosyltransferase alleles nomenclature homepage. Available online: http://www.pharmacogenomics.pha.ulaval.ca/sgc/ugt_alleles/lang/en_CA/, (accessed on 17 May 2010).

64. Evans, W.E.; Relling, M.V. Pharmacogenomics: translating functional genomics into rational therapeutics. Science 1999, 286, 487-491.

65. Mackenzie, P.I.; Gregory, P.A.; Lewinsky, R.H.; Yasmin, S.N.; Height, T.; McKinnon, R.A.; Gardner-Stephen, D.A. Polymorphic variations in the expression of the chemical detoxifying UDP glucuronosyltransferases. Toxicol. Appl. Pharmacol. 2005, 207, 77-83.

66. Argikar, U.A.; Iwuchukwu, O.F.; Nagar, S. Update on tools for evaluation of uridine diphosphoglucuronosyltransferase polymorphisms. Expert Opin. Drug Metab. Toxicol. 2008, 4, 879-894.

67. Chung, J.Y.; Cho, J.Y.; Yu, K.S.; Kim, J.R.; Lim, K.S.; Sohn, D.R.; Shin, S.G.; Jang, I.J. Pharmacokinetic and pharmacodynamic interaction of lorazepam and valproic acid in relation to UGT2B7 genetic polymorphism in healthy subjects. Clin. Pharmacol. Ther. 2008, 83, 595-600.

68. Staines, A.G.; Coughtrie, M.W.; Burchell, B. N-glucuronidation of carbamazepine in human tissues is mediated by UGT2B7. J. Pharmacol. Exp. Ther. 2004, 311, 1131-1137. 
69. Rowland, A.; Elliot, D.J.; Williams, J.A.; Mackenzie, P.I.; Dickinson, R.G.; Miners, J.O. In vitro characterization of lamotrigine $N 2$-glucuronidation and the lamotrigine-valproic acid interaction. Drug Metab. Dispos. 2006, 34, 1055-1062.

70. Bhasker, C.R.; McKinnon, W.; Stone, A.; Lo, A.C.; Kubota, T.; Ishizaki, T.; Miners, J.O. Genetic polymorphism of UDP-glucuronosyltransferase 2B7 (UGT2B7) at amino acid 268: ethnic diversity of alleles and potential clinical significance. Pharmacogenetics 2000, 10, 679-685.

71. Duguay, Y.; Baar, C.; Skorpen, F.; Guillemette, C. A novel functional polymorphism in the uridine diphosphate-glucuronosyltransferase 2B7 promoter with significant impact on promoter activity. Clin. Pharmacol. Ther. 2004, 75, 223-233.

72. Holthe, M.; Rakvag, T.N.; Klepstad, P.; Idle, J.R.; Kaasa, S.; Krokan, H.E.; Skorpen, F. Sequence variations in the UDP-glucuronosyltransferase 2B7 (UGT2B7) gene: identification of 10 novel single nucleotide polymorphisms (SNPs) and analysis of their relevance to morphine glucuronidation in cancer patients. Pharmacogenomics J. 2003, 3, 17-26.

73. Saeki, M.; Saito, Y.; Jinno, H.; Tanaka-Kagawa, T.; Ohno, A.; Ozawa, S.; Ueno, K.; Kamakura, S.; Kamatani, N.; Komamura, K.; Kitakaze, M.; Sawada, J. Single nucleotide polymorphisms and haplotype frequencies of UGT2B4 and UGT2B7 in a Japanese population. Drug Metab. Dispos. 2004, 32, 1048-1054.

74. Innocenti, F.; Liu, W.; Fackenthal, D.; Ramirez, J.; Chen, P.; Ye, X.; Wu, X.; Zhang, W.; Mirkov, S.; Das, S.; Cook, E., Jr.; Ratain, M.J. Single nucleotide polymorphism discovery and functional assessment of variation in the UDP-glucuronosyltransferase 2B7 gene. Pharmacogenet. Genomics 2008, 18, 683-697.

75. Whalen, R.; Boyer, T.D. Human glutathione S-transferases. Semin. Liver Dis. 1998, 18, 345-358.

76. Bolt, H.M.; Thier, R. Relevance of the deletion polymorphisms of the glutathione S-transferases GSTT1 and GSTM1 in pharmacology and toxicology. Curr. Drug Metab. 2006, 7, 613-628.

77. Reszka, E.; Wasowicz, W.; Gromadzinska, J. Genetic polymorphism of xenobiotic metabolising enzymes, diet and cancer susceptibility. Br. J. Nutr. 2006, 96, 609-619.

78. Ginsberg, G.; Smolenski, S.; Hattis, D.; Guyton, K.Z.; Johns, D.O.; Sonawane, B. Genetic Polymorphism in Glutathione Transferases (GST): Population distribution of GSTM1, T1, and P1 conjugating activity. J. Toxicol. Environ. Health B Crit. Rev. 2009, 12, 389-439.

79. Eichelbaum, M.; Tomson, T.; Tybring, G.; Bertilsson, L. Carbamazepine metabolism in man. Induction and pharmacogenetic aspects. Clin. Pharmacokinet. 1985, 10, 80-90.

80. Tomson, T.; Tybring, G.; Bertilsson, L. Single-dose kinetics and metabolism of carbamazepine10,11-epoxide. Clin. Pharmacol. Ther. 1983, 33, 58-65.

81. Kerr, B.M.; Thummel, K.E.; Wurden, C.J.; Klein, S.M.; Kroetz, D.L.; Gonzalez, F.J.; Levy, R.H. Human liver carbamazepine metabolism. Role of CYP3A4 and CYP2C8 in 10,11-epoxide formation. Biochem. Pharmacol. 1994, 47, 1969-1979.

82. Kang, P.; Liao, M.; Wester, M.R.; Leeder, J.S.; Pearce, R.E.; Correia, M.A. CYP3A4-Mediated carbamazepine (CBZ) metabolism: formation of a covalent CBZ-CYP3A4 adduct and alteration of the enzyme kinetic profile. Drug Metab. Dispos. 2008, 36, 490-499.

83. Elger, C.E.; Schmidt, D. Modern management of epilepsy: a practical approach. Epilepsy Behav. 2008, 12, 501-539. 
84. Makmor-Bakry, M.; Sills, G.J.; Hitiris, N.; Butler, E.; Wilson, E.A.; Brodie, M.J. Genetic variants in microsomal epoxide hydrolase influence carbamazepine dosing. Clin. Neuropharmacol. 2009, 32, 205-212.

85. U.S. Food and Drug Administration. Information for Healthcare Professionals: Dangerous or Even Fatal Skin Reactions - Carbamazepine (marketed as Carbatrol, Equetro, Tegretol, and generics). Available online:http://www.fda.gov/Drugs/DrugSafety/PostmarketDrugSafetyI nformationforPatientsandProviders/ucm124718.htm/, (accessed on 03 August 2010).

86. Hung, S.I.; Chung, W.H.; Jee, S.H.; Chen, W.C.; Chang, Y.T.; Lee, W.R.; Hu, S.L.; Wu, M.T.; Chen, G.S.; Wong, T.W.; et al. Genetic susceptibility to carbamazepine-induced cutaneous adverse drug reactions. Pharmacogenet. Genomics 2006, 16, 297-306.

87. Zaccara, G.; Franciotta, D.; Perucca, E. Idiosyncratic adverse reactions to antiepileptic drugs. Epilepsia 2007, 48, 1223-1244.

88. Ueda, K.; Ishitsu, T.; Seo, T.; Ueda, N.; Murata, T.; Hori, M.; Nakagawa, K. Glutathione Stransferase M1 null genotype as a risk factor for carbamazepine-induced mild hepatotoxicity. Pharmacogenomics 2007, 8, 435-442.

89. Kilpatrick, C.; Bury, R.; Fullinfaw, R.; Moulds, R. Clobazam in the treatment of epilepsy. Clin. Exp. Neurol. 1987, 23, 139-144.

90. Ng, Y.T.; Collins, S.D. Clobazam. Neurotherapeutics 2007, 4, 138-144.

91. Giraud, C.; Tran, A.; Rey, E.; Vincent, J.; Treluyer, J.M.; Pons, G. In vitro characterization of clobazam metabolism by recombinant cytochrome P450 enzymes: importance of CYP2C19. Drug Metab. Dispos. 2004, 32, 1279-1286.

92. Canadian Clobazam Cooperative Group. Clobazam in treatment of refractory epilepsy: the Canadian experience. A retrospective study. Epilepsia 1991, 32, 407-416.

93. Remy, C. Clobazam in the treatment of epilepsy: a review of the literature. Epilepsia 1994, 35, 88-91.

94. Shorvon, S.D. The use of clobazam, midazolam, and nitrazepam in epilepsy. Epilepsia 1998, 39, $15-23$.

95. Magdalou, J.; Herber, R.; Bidault, R.; Siest, G. In vitro N-glucuronidation of a novel antiepileptic drug, lamotrigine, by human liver microsomes. J. Pharmacol. Exp. Ther. 1992, 260, 1166-1173.

96. Posner, J.; Cohen, A.F.; Land, G.; Winton, C.; Peck, A.W. The pharmacokinetics of lamotrigine (BW430C) in healthy subjects with unconjugated hyperbilirubinaemia (Gilbert's syndrome). Br. J. Clin. Pharmacol. 1989, 28, 117-120.

97. Blanca Sanchez, M.; Herranz, J.L.; Leno, C.; Arteaga, R.; Oterino, A.; Valdizan, E.M.; Nicolas, J.M.; Adin, J.; Shushtarian, M.; Armijo, J.A. UGT2B7_-161C $>$ T polymorphism is associated with lamotrigine concentration-to-dose ratio in a multivariate study. Ther. Drug Monit. 2010, 32, 177-184.

98. Maguire, J.H. Quantitative estimation of catechol/methylcatechol pathways in human phenytoin metabolism. Epilepsia 1988, 29, 753-759.

99. Bajpai, M.; Roskos, L.K.; Shen, D.D.; Levy, R.H. Roles of cytochrome P450 2C9 and cytochrome P4502C19 in the stereoselective metabolism of phenytoin to its major metabolite. Drug Metab. Dispos. 1996, 24, 1401-1403. 
100. Odani, A.; Hashimoto, Y.; Otsuki, Y.; Uwai, Y.; Hattori, H.; Furusho, K.; Inui, K. Genetic polymorphism of the CYP2C subfamily and its effect on the pharmacokinetics of phenytoin in Japanese patients with epilepsy. Clin. Pharmacol. Ther. 1997, 62, 287-292.

101. van der Weide, J.; Steijns, L.S.; van Weelden, M.J.; de Haan, K. The effect of genetic polymorphism of cytochrome P450 CYP2C9 on phenytoin dose requirement. Pharmacogenetics 2001, 11, 287-291.

102. Aynacioglu, A.S.; Brockmoller, J.; Bauer, S.; Sachse, C.; Guzelbey, P.; Ongen, Z.; Nacak, M.; Roots, I. Frequency of cytochrome P450 CYP2C9 variants in a Turkish population and functional relevance for phenytoin. Br. J. Clin. Pharmacol. 1999, 48, 409-415.

103. Tate, S.K.; Depondt, C.; Sisodiya, S.M.; Cavalleri, G.L.; Schorge, S.; Soranzo, N.; Thom, M.; Sen, A.; Shorvon, S.D.; Sander, J.W.; Wood, N.W.; Goldstein, D.B. Genetic predictors of the maximum doses patients receive during clinical use of the anti-epileptic drugs carbamazepine and phenytoin. Proc. Natl. Acad. Sci. USA 2005, 102, 5507-5512.

104. Chaudhry, A.S.; Urban, T.J.; Lamba, J.K.; Birnbaum, A.K.; Remmel, R.P.; Subramanian, M.; Strom, S.; You, J.H.; Kasperaviciute, D.; Catarino, C.B.; Radtke, R.A.; Sisodiya, S.M.; Goldstein, D.B.; Schuetz, E.G., CYP2C9*1B promoter polymorphisms, in linkage with CYP2C19*2, affect phenytoin autoinduction of clearance and maintenance dose. J. Pharmacol. Exp. Ther. 2010, 332, 599-611.

105. Ninomiya, H.; Mamiya, K.; Matsuo, S.; Ieiri, I.; Higuchi, S.; Tashiro, N. Genetic polymorphism of the CYP2C subfamily and excessive serum phenytoin concentration with central nervous system intoxication. Ther. Drug Monit. 2000, 22, 230-232.

106. Brandolese, R.; Scordo, M.G.; Spina, E.; Gusella, M.; Padrini, R. Severe phenytoin intoxication in a subject homozygous for CYP2C9*3. Clin. Pharmacol. Ther. 2001, 70, 391-394.

107. Kidd, R.S.; Curry, T.B.; Gallagher, S.; Edeki, T.; Blaisdell, J.; Goldstein, J.A. Identification of a null allele of CYP2C9 in an African-American exhibiting toxicity to phenytoin. Pharmacogenetics 2001, 11, 803-808.

108. Ramasamy, K.; Narayan, S.K.; Chanolean, S.; Chandrasekaran, A. Severe phenytoin toxicity in a CYP2C9*3*3 homozygous mutant from India. Neurol. India 2007, 55, 408-409.

109. Lee, A.Y.; Kim, M.J.; Chey, W.Y.; Choi, J.; Kim, B.G. Genetic polymorphism of cytochrome P450 2C9 in diphenylhydantoin-induced cutaneous adverse drug reactions. Eur. J. Clin. Pharmacol. 2004, 60, 155-159.

110. Soga, Y.; Nishimura, F.; Ohtsuka, Y.; Araki, H.; Iwamoto, Y.; Naruishi, H.; Shiomi, N.; Kobayashi, Y.; Takashiba, S.; Shimizu, K.; Gomita, Y.; Oka, E. CYP2C polymorphisms, phenytoin metabolism and gingival overgrowth in epileptic subjects. Life Sci. 2004, 74, 827-834.

111. Lin, C.J.; Yen, M.F.; Hu, O.Y.; Lin, M.S.; Hsiong, C.H.; Hung, C.C.; Liou, H.H. Association of galactose single-point test levels and phenytoin metabolic polymorphisms with gingival hyperplasia in patients receiving long-term phenytoin therapy. Pharmacotherapy 2008, 28, 35-41.

112. Kwan, P.; Brodie, M.J. Phenobarbital for the treatment of epilepsy in the 21 st century: a critical review. Epilepsia 2004, 45, 1141-1149.

113. Anderson, G.D. Pharmacogenetics and enzyme induction/inhibition properties of antiepileptic drugs. Neurology 2004, 63, 3-8. 
114. Mamiya, K.; Hadama, A.; Yukawa, E.; Ieiri, I.; Otsubo, K.; Ninomiya, H.; Tashiro, N.; Higuchi, S. CYP2C19 polymorphism effect on phenobarbitone. Pharmacokinetics in Japanese patients with epilepsy: analysis by population pharmacokinetics. Eur. J. Clin. Pharmacol. 2000, 55, 821-825.

115. Heller, A.J.; Chesterman, P.; Elwes, R.D.; Crawford, P.; Chadwick, D.; Johnson, A.L.; Reynolds, E.H. Phenobarbitone, phenytoin, carbamazepine, or sodium valproate for newly diagnosed adult epilepsy: a randomised comparative monotherapy trial. J. Neurol. Neurosurg. Psychiatry 1995, 58, 44-50.

116. de Silva, M.; MacArdle, B.; McGowan, M.; Hughes, E.; Stewart, J.; Neville, B.G.; Johnson, A.L.; Reynolds, E.H. Randomised comparative monotherapy trial of phenobarbitone, phenytoin, carbamazepine, or sodium valproate for newly diagnosed childhood epilepsy. Lancet 1996, 347, 709-713.

117. Nimaga, K.; Desplats, D.; Doumbo, O.; Farnarier, G. Treatment with phenobarbital and monitoring of epileptic patients in rural Mali. Bull. World Health Organ. 2002, 80, 532-537.

118. Wang, W.Z.; Wu, J.Z.; Ma, G.Y.; Dai, X.Y.; Yang, B.; Wang, T.P.; Yuan, C.L.; Hong, Z.; Bell, G.S.; Prilipko, L.; de Boer, H.M.; Sander, J.W. Efficacy assessment of phenobarbital in epilepsy: a large community-based intervention trial in rural China. Lancet Neurol. 2006, 5, 46-52.

119. Chadwick, D.W. Concentration-effect relationships of valproic acid. Clin. Pharmacokinet. 1985, 10, 155-163.

120. Jiang, D.; Bai, X.; Zhang, Q.; Lu, W.; Wang, Y.; Li, L.; Muller, M. Effects of CYP2C19 and CYP2C9 genotypes on pharmacokinetic variability of valproic acid in Chinese epileptic patients: nonlinear mixed-effect modeling. Eur. J. Clin. Pharmacol. 2009, 65, 1187-1193.

121. Jin, C.; Miners, J.O.; Lillywhite, K.J.; Mackenzie, P.I. Complementary deoxyribonucleic acid cloning and expression of a human liver uridine diphosphate-glucuronosyltransferase glucuronidating carboxylic acid-containing drugs. J. Pharmacol. Exp. Ther. 1993, 264, 475-479.

122. Rettie, A.E.; Rettenmeier, A.W.; Howald, W.N.; Baillie, T.A. Cytochrome P-450-catalyzed formation of delta 4-VPA, a toxic metabolite of valproic acid. Science 1987, 235, 890-893.

123. Sadeque, A.J.; Fisher, M.B.; Korzekwa, K.R.; Gonzalez, F.J.; Rettie, A.E. Human CYP2C9 and CYP2A6 mediate formation of the hepatotoxin 4-ene-valproic acid. J. Pharmacol. Exp. Ther. 1997, 283, 698-703.

124. Tong, V.; Teng, X.W.; Chang, T.K.; Abbott, F.S. Valproic acid I: time course of lipid peroxidation biomarkers, liver toxicity, and valproic acid metabolite levels in rats. Toxicol. Sci. 2005, 86, 427-435.

125. Fukushima, Y.; Seo, T.; Hashimoto, N.; Higa, Y.; Ishitsu, T.; Nakagawa, K. Glutathione-Stransferase (GST) M1 null genotype and combined GSTM1 and GSTT1 null genotypes are risk factors for increased serum gamma-glutamyltransferase in valproic acid-treated patients. Clin. Chim. Acta 2008, 389, 98-102.

126. Hachad, H.; Ragueneau-Majlessi, I.; Levy, R.H. New antiepileptic drugs: review on drug interactions. Ther. Drug Monit. 2002, 24, 91-103.

127. Baulac, M. Introduction to zonisamide. Epilepsy Res. 2006, 68, 3-9.

128. Nakasa, H.; Nakamura, H.; Ono, S.; Tsutsui, M.; Kiuchi, M.; Ohmori, S.; Kitada, M. Prediction of drug-drug interactions of zonisamide metabolism in humans from in vitro data. Eur. J. Clin. Pharmacol. 1998, 54, 177-183. 
129. Aarons, L. Population pharmacokinetics: theory and practice. Br. J. Clin. Pharmacol. 1991, 32, 669-670.

130. Kohle, C.; Bock, K.W. Coordinate regulation of human drug-metabolizing enzymes, and conjugate transporters by the $\mathrm{Ah}$ receptor, pregnane $\mathrm{X}$ receptor and constitutive androstane receptor. Biochem. Pharmacol. 2009, 77, 689-699.

131. Ingelman-Sundberg, M.; Sim, S.C.; Gomez, A.; Rodriguez-Antona, C. Influence of cytochrome P450 polymorphisms on drug therapies: pharmacogenetic, pharmacoepigenetic and clinical aspects. Pharmacol. Ther. 2007, 116, 496-526.

132. Gomez, A.; Ingelman-Sundberg, M. Pharmacoepigenetics: its role in interindividual differences in drug response. Clin. Pharmacol. Ther. 2009, 85, 426-430.

133. Urdinguio, R.G.; Sanchez-Mut, J.V.; Esteller, M. Epigenetic mechanisms in neurological diseases: genes, syndromes, and therapies. Lancet Neurol. 2009, 8, 1056-1072.

134. Urban, T.J.; Brown, C.; Castro, R.A.; Shah, N.; Mercer, R.; Huang, Y.; Brett, C.M.; Burchard, E.G.,; Giacomini, K.M. Effects of genetic variation in the novel organic cation transporter, OCTN1, on the renal clearance of gabapentin. Clin. Pharmacol. Ther. 2008, 83, 416-421.

(C) 2010 by the authors; licensee MDPI, Basel, Switzerland. This article is an Open Access article distributed under the terms and conditions of the Creative Commons Attribution license (http://creativecommons.org/licenses/by/3.0/). 